\title{
Analisis de los diseños y contenidos curriculares para la enseñanza de la química en las instituciones de educación media en relación con las modalidades academicas
}

Peralta Burgos Fredy Alberto' y Parga Diana Lineth²

\section{Resumen}

La enseñanza de la química en las instituciones de educación media permite realizar un análisis entre la formación académica del estudiante y su desarrollo como persona en la sociedad, a partir del enfoque pedagógico, epistemológico y filosófico que desarrollan las instituciones educativas en sus Proyectos educativos institucionales (PEI) Los colegios presentan entre otras cosas el perfil de la persona que desea formar, para esto algunas instituciones cuentan con modalidades académicas como por ejemplo; la agrícola, técnica, en Ciencias Naturales o con principios y valores cristiano - católicos, donde enfocan los contenidos curriculares de todas las áreas de su currículo en el desarrollo de estas, del mismo modo se puede determinar si la selección de contenidos, su secuencia y el desarrollo de esta en el aula, atiende a los intereses y necesidades de los estudiantes.

\section{Palabras claves}

Diseños curriculares, Intereses, Necesidades, Enseñanza de la química, modalidad académica, educación media.

\section{Introducción}

El proceso de enseñanza y aprendizaje de las ciencias experimentales, en particular la química, se inicia a partir de la educación media, convirtiéndose en el primer contacto, bien sea teórico o experimental del estudiante con esta área del conocimiento. Es de resaltar que algunas nociones de esta ciencia son orientadas en grados inferiores. La enseñanza de la química en este nivel permitirá identificar relaciones entre las ciencias experimentales y la didáctica de las ciencias; por lo tanto, se busca analizar si los contenidos y la secuencia de los

1 Estudiante de Maestría en Docencia de la Química. Universidad Pedagógica Nacional, Bogotá.

2 Profesora del Departamento de Química. Universidad Pedagógica Nacional, Bogotá. 
Revista Tecné, Episteme y Didaxis: TED. Año 2014, Número Extraordinario. ISSN Impreso: 0121-3814, ISSN web: 2323-0126

Memorias, Sexto Congreso Internacional sobre Formación de Profesores de Ciencias. 08 al 10 de octubre de 2014, Bogotá

mismos, son pertinentes y se relacionan con las necesidades e intereses de los estudiantes así como la modalidad académica que resalta las instituciones en su Proyecto Educativo Institucional (PEI). Este análisis permitirá interiorizar en el desempeño docente, cuáles son los criterios que tiene presentes cuando hacen la selección y secuencia de contenidos y cuál es el papel de la enseñanza de la química en el desarrollo de una determinada modalidad académica.

Para este análisis se seleccionarán cuatro colegios en la ciudad de Fusagasugá Cundinamarca, donde se implemente la educación media; estas instituciones presentan aspectos contextuales muy distintos, ya que se parte de las condiciones sociales diferentes y se atiende a la modalidad que caracteriza al colegio bien sea Agrícola, religiosa, técnica y enfocada en las Ciencias Naturales, esta serie de aspectos conducirán a identificar cuál es el papel que juega la química en estas comunidades educativas, que ocurre con los intereses y necesidades de los estudiantes de un colegio público agrícola en un sector con bajas condiciones económicas, en relación con un colegio privado religioso de un alto nivel social, qué tipo de dificultades presentan en su aprendizaje y qué criterios basados en esos contextos aplica el docente a partir de la enseñanza de la química.

Los objetivos principales de esta investigación son:

$>$ Analizar el currículo de química en cinco instituciones educativas de la ciudad de Fusagasugá/ Cundinamarca y su relación con los intereses del estudiantado al escoger una modalidad académica propia de la institución

> Analizar los contenidos curriculares de la química de los grados décimo y undécimo, a partir de la modalidad académica dada en cuatro colegios de educación media de la ciudad de Fusagasugá/ Cundinamarca

> Evaluar la pertinencia del currículo con respecto a las necesidades e intereses de las comunidades analizadas.

\section{Marco teórico}

Sánchez y Valcárcel (1993) plantean que todo contenido seleccionado para ser llevado al aula, es secuenciado en unidades didácticas que permite preparar una lección; en todo caso, esto es una tarea que ha de llevar a cabo el docente. Es por ello que el profesorado debe preguntarse por los siguientes aspectos: cuáles deben ser los contenidos a incluir en la lección o clase, por dónde 
Revista Tecné, Episteme y Didaxis: TED. Año 2014, Número Extraordinario. ISSN Impreso: 0121-3814, ISSN web: 2323-0126

Memorias, Sexto Congreso Internacional sobre Formación de Profesores de Ciencias. 08 al 10 de octubre de 2014, Bogotá

comienza su desarrollo, qué experiencias de laboratorio debo hacer. Para los autores es necesario que el docente este en la capacidad de implementar el diseño de unidades didácticas en el área de ciencias experimentales, para lo cual proponen un modelo, que consiste en tener claro unos objetivos y unos procedimientos dentro de cinco niveles secuenciales que los describen así: (I) análisis científico, (II) análisis didáctico, (III) selección de objetivos, (IV) selección de estrategias didácticas y (V) selección de estrategias de evaluación.

\section{Los modelos didácticos}

La enseñanza de la ciencias experimentales parte de un análisis fundamental: reflexionar lo que implica enseñar una ciencia realizada por expertos, determinar qué factores son necesarios para que dicho conocimiento sea fácil, comprensible y no se aleje de su verdadera naturaleza, además pueda ser orientado a personas no expertas ni con la experiencia suficiente, para describir el lenguaje científico. Así mismo es necesario trasformar el conocimiento científico en un conocimiento escolar mediante uno de los modelos didácticos, estos últimos no se corresponden con la ciencia misma de los científicos, sino una reconstrucción de ésta, al mismo tiempo que tampoco es un reflejo de los saberes cotidianos de los alumnos (Chamizo, 2010).

\section{Diseño curricular}

Generalmente es el docente el responsable de este proceso, el cual lo lleva a interrogarse sobre el proceso que diseñará, por ejemplo, el determinar qué tipo de contenido en química y cuál es la secuencia temática, qué en orden académico permitirá construir nuevos conocimientos a partir de los ya existentes, cuáles son los objetivos y los criterios que le permiten afirmar la importancia del contenido seleccionado en la formación de estudiantes. Se considera, como guía ideal para diseño curricular, el Análisis científico, análisis didáctico, selección de objetivos, selección de estrategias didácticas, selección de estrategias de evaluación (Sánchez y Valcárcel, 1993).

\section{El conocimiento didáctico del contenido}

El docente es quien conoce la verdadera distancia entre la ciencia erudita y la ciencia escolar y es el responsable directo en la construcción y significación de un nuevo conocimiento científico, lo anterior implica que no basta con conocer a la perfección una ciencia, es necesario conocer y aplicar la didáctica en cada uno de los contenidos seleccionados, es necesario identificar los intereses y 
Revista Tecné, Episteme y Didaxis: TED. Año 2014, Número Extraordinario. ISSN Impreso: 0121-3814, ISSN web: 2323-0126

Memorias, Sexto Congreso Internacional sobre Formación de Profesores de Ciencias. 08 al 10 de octubre de 2014, Bogotá

necesidades de sus estudiantes, tener todo una análisis contextual, que lo puede fortalecer a partir del conocimiento didáctico del contenido, un concepto propuesto inicialmente por Lee S. Shulman en 1983 y que se considera clave para la investigación y la mejora de la práctica docente del profesorado. El CDC es un elemento central del conocimiento del profesor y resulta fundamental hoy para promover el desarrollo profesional del profesorado de ciencias (Acevedo, 2008).

Uno de los aspecto que se considera con mayor importancia en CDC es el conocimiento por parte del docente sobre los aspectos histórico epistemológicos, lo cual permite una visión profunda de los aspectos relevantes en el desarrollo de una teoría, así mismo presenta una ciencia humana y no un resultado espontaneo deshumanizado a los estudiantes, partiendo de los simple a lo complejo, se comparte la idea sobre necesidad construir tramas histórico-epistemológicas como paso previo a la construcción de unidades didácticas (Mora y Parga, 2007).

\section{Colombia y su visión sobre educación}

Es importante analizar si desde la entidad de mayor control en educación en Colombia existen como punto de partida los intereses y necesidades atiendo a las características sociales, se puede resaltar que actualmente se han planteado objetivos que buscan, definir tres estrategias de gran impacto en la educación del país: cobertura, calidad y eficiencia, cuyo objetivo es transformar el sistema educativo en magnitud y pertinencia para garantizar la competitividad del país, conseguir una mayor calidad de vida y mayor equidad social según contenido en la página web la Revolución Educativa.

\section{Fases de la investigación}

Dado que el presente trabajo será un proceso continuo de análisis y de decisiones del investigador, quien hará el papel de facilitador mientras realiza un seguimiento detallado de los diarios, reuniones de grupos y documentos a fines a todo aspecto curricular del contenido didáctico en química, con el método a usar y las técnicas de recolección de información que permitan hacer observaciones adecuadas, entre otras, para finalmente dejar al descubierto el significado que los sujetos ofrecen de sus propias experiencias frente al diseño curricular y la selección de los contenidos; para ello, se han propuesto como fases las siguientes: fase diagnóstica, fase de propuesta y fase de evaluación. 
Revista Tecné, Episteme y Didaxis: TED. Año 2014, Número Extraordinario. ISSN Impreso: 0121-3814, ISSN web: 2323-0126

Memorias, Sexto Congreso Internacional sobre Formación de Profesores de Ciencias. 08 al 10 de octubre de 2014, Bogotá

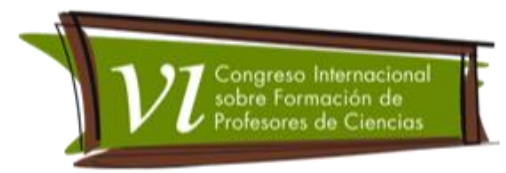

\section{Fase diagnóstica}

Partiendo del conocimiento general de la estructura de planes curriculares que permitan integrar las opiniones de acuerdo con intereses y necesidades del estudiantado y la comunidad educativa, se pretende analizar los diseños curriculares por instituciones educativas en el área de química, interiorizar en el contexto y con el apoyo de docentes, directivos, padres de familia y estudiantes como una sociedad que debe estar comprometida con el desarrollo de la educación.

Las técnicas para la recolección de información en esta fase son:

Análisis documental: Se realiza el análisis de los documentos fundamentales de cuatro instituciones educativas como el Proyecto Educativo Institucional (PEI) los planes de Estudio o mallas curriculares, así como las actas de las reuniones del área de Ciencias Naturales, para determinar la relación que existe entre estos documentos y el aporte de la enseñanza de la química a las diferentes modalidades académicas.

Encuesta: Será realizada a los docentes, estudiantes, coordinadores o rectores y padres de familia, implicados principales en el proceso enseñanza-aprendizaje, esta técnica permite informar con precisión y claridad sus propias observaciones del mundo real que los rodea.

Diario de Campo: El investigador realiza las observaciones en el contexto directo a investigar, analizando las diferentes situaciones por mínimas que sean; permite identificar aspectos sociales, desarrollo de los contenidos en el aula, metodología de aprendizaje, ambientes de aprendizaje, recursos didácticos y todo aspecto que como investigador considere relevante.

Entrevistas: El investigador hará un muestreo general del panorama escolar, para identificar en los profesores sus conocimientos frente a la didáctica del contenido, sus experiencias. En el estudiante busca identificar cuáles son sus necesidades e intereses como proyección para su proyecto de vida.

\section{Fase diseño de propuesta}

Para identificar cuáles son los verdaderos alcances de la enseñanza de la química en la educación media, se considera como principal, partir del análisis documental, así como su secuenciación y diseño, determinar si es su planeación, los intereses y necesidades del estudiantado, acudiendo a sus condiciones 
Revista Tecné, Episteme y Didaxis: TED. Año 2014, Número Extraordinario. ISSN Impreso: 0121-3814, ISSN web: 2323-0126

Memorias, Sexto Congreso Internacional sobre Formación de Profesores de Ciencias. 08 al 10 de octubre de 2014, Bogotá

sociales son tenidos en cuenta por el docente, como puede la planeación de los contenidos abordar la problemática del aprendizaje, para plantear posibles soluciones. Para el diseño de la propuesta se determina el estudio de casos de cuatro instituciones de educación media vocacional.

\section{Fase evaluación de la propuesta}

Teniendo en cuenta que la mayoría de los procesos y transformaciones en el campo educativo se realizan paulatinamente con relación al tiempo, más que evaluar la aparición de caracteres de orden pedagógico y didáctico, lo que se busca analizar por medio de la construcción de propuestas que faciliten el aprendizaje de las ciencias experimentales, a partir de los intereses y necesidades de los estudiantes y que además a porten a la problemática dela enseñanza en esta ciencia, y a la formación profesional de los profesores.

\section{Conclusiones}

Identificar si los contenidos y diseños curriculares, parten de los intereses y necesidades de los estudiantes, a partir de su estudio crítico y analítico de la secuenciación que realiza cada docente en la diferentes instituciones de educación media, de igual forma se busca analizar como interviene la modalidad de las instituciones en la enseñanza de la química, según la estructura de los proyectos educativos institucionales, por otra lado el determinar cómo se desarrolla el conocimiento didáctico del contenido cuando atiende a los intereses y necesidades de una comunidad en relación con la modalidad académica de la institución.

Caracterizar los criterios más sobresalientes que tienen los docentes al seleccionar y secuenciar contenidos, permite evidenciar como desarrollan su propio conocimiento didáctico del contenido y como este puede aportar al aprendizaje Significativo de las ciencias, en particular la química.

\section{Referentes bibliograficos}

Bartolomé, V. B.; Jiménez, P.; Mellado, V.; Taboada, L. (2007). Análisis de las secuencias de actividades: reflexión e intervención en el aula de Ciencias. El caso de una profesora de secundaria Revista Electrónica de Enseñanza de las Ciencias Vol. 6, N³, 649-672 (2007) 649.

Mora, W. y Parga, D. (2008). El conocimiento didáctico del contenido en química: integración de las tramas de contenido histórico-epistemológicas con las 
Revista Tecné, Episteme y Didaxis: TED. Año 2014, Número Extraordinario. ISSN Impreso: 0121-3814, ISSN web: 2323-0126

Memorias, Sexto Congreso Internacional sobre Formación de Profesores de Ciencias. 08 al 10 de octubre de 2014, Bogotá

tramas de contexto-aprendizaje. En Tecné, Episteme y Didaxis: TED 24, p. 5681.

Mora, W. y Parga, D. (2009). La imagen publica de la química y su relación con la generación de actitudes hacia la química y su aprendizaje. En Tecné, Episteme y Didaxis: TED, 27, p.67-93.

Chamizo, J.A. (2010). Una tipología de los modelos para la enseñanza de las ciencias En Eureka sobre Enseñanza y Divulgación de las Ciencias, vol. 7(1), p. 26-41.

Shulman, L. S. (1987). Knowledge and teaching: foundations of the new reform. Harvard Educational Review, 57(1), 1-22. Traducción castellana (2005): Conocimiento y enseñanza: fundamento de la nueva reforma. Profesorado. Revista de Currículum y Formación de Profesorado, 9(2), http://www.ugr.es/ recfpro/rev92ART1.pdf. 